\title{
Soroprevalência de Babesia bovis em bovinos na mesorregião Norte Fluminense ${ }^{1}$
}

\author{
Cleber O. Soares ${ }^{2}$, José Carlos P. Souza², Claúdio R. Madruga ${ }^{3}$, Renata C. \\ Madureira $^{4}$, Carlos L. Massard ${ }^{2}$ e Adivaldo H. Fonseca ${ }^{2}$
}

\begin{abstract}
Soares C.O., Souza J.C.P., Madruga C.R., Madureira R.C., Massard C.L. \& Fonseca A.H. 2000. [Seroprevalence of Babesia bovis in cattle in the "Norte Fluminense" mesoregion.] Soroprevalência de Babesia bovis em bovinos na mesorregião Norte Fluminense. Pesquisa Veterinária Brasileira 20(2):75-79. Depto Parasitologia Animal, Univ. Fed. Rural do Rio de Janeiro, Km 47, Seropédica, RJ 23890-000, Brazil.

Serumprevalence of antibodies against Babesia bovis were studied by the indirect EnzymeLinked Immunosorbent Assay (ELISA). Sera samples from 532 bovines of nine municipalities in the "Norte Fluminense" mesoregion, state of Rio de Janeiro, were analysed. The results showed that $484(90.98 \%)$ were positive by indirect ELISA, of which were: $20.30 \%$ with a titre of $1: 500,35.72 \%$ of $1: 1000,20.87 \%$ of $1: 2000,7.33 \%$ of $1: 4000,2.82 \%$ of $1: 8000,2.63 \%$ of $1: 16000,0.56 \%$ of $1: 32000,0.75 \%$ of $1: 64000$, and $9.02 \%$ were negative. The prevalence analysis was done within three age groups: 1 to 3 years $(n=110), 3$ to 6 years $(n=241)$ and $>6$ years $(n=181)$, of which $98.18 \%, 90.87 \%$ and $86.74 \%$ were positive, respectively. There were significant differences $(\mathrm{P}<0,05)$ between the 1 to 3 year-group and other age groups. The young animals are less susceptible to the disease than older animals. According to the breed, $91.44 \%$ of beef cattle $(n=444)$ and $88.64 \%$ of dairy cattle $(n=88)$ were positive. Regarding the sex, $90.54 \%$ of the females $(n=497)$ and $97.14 \%$ of the males $(n=35)$ were positive. There were no significant differences between breeding types and the sexes $(P>0.05)$. There were significant differences $(\mathrm{P}<0.0001)$ between the prevalence in the different municipalities. The infection by $B$. bovis in this mesoregion is heterogeneous, although the seroprevalence showed that the region has to be considered enzootically stable. The epidemiological situation requires immunization only of animals coming from other areas.
\end{abstract}

INDEX TERMS: Seroepidemiology, Babesia bovis, bovine babesiosis, enzyme immunoassay, "Norte Fluminense" mesoregion, Brazil.

RESUMO.- Estudou-se a soroprevalência de anticorpos anti Babesia bovis em bovinos de nove municípios na mesorregião Norte Fluminense do estado do Rio de Janeiro. Realizou-se o ensaio de imunoadsorção enzimática (ELISA) indireto em 532 amostras de soro de bovinos. A análise soroepidemiológica revelou $484(90,98 \%)$ animais reagentes positivos ao ELISA indireto, dos quais: $20,30 \%$ com título de $1: 500,35,72 \%$ com

\footnotetext{
${ }^{1}$ Aceito para publicação em 29 de setembro de 1999.

${ }^{2}$ Curso de Pós-Graduação em Medicina Veterinária - Parasitologia Veterinária, Universidade Federal Rural do Rio de Janeiro (UFRRJ). Km 47, Seropédica, RJ 23890-000; e-mail: csoares@ufrrj.br

${ }^{3}$ Centro Nacional de Pesquisa de Gado de Corte, Embrapa, Campo Grande, MS.

${ }^{4}$ Acadêmica de Medicina Veterinária da UFRRJ, Bolsista de Iniciação Científica PIBIC / UFRRJ / CNPq.
}

título de 1:1000, 20,87\% com título de 1:2000, 7,33\% com título de 1:4000, 2,82\% com título de 1:8000, 2,63\% com título de 1:16000, 0,56\% com título de 1:32000, 0,75\% com título de 1:64000 e 9,02\% foram negativos. A análise da prevalência segundo a faixa etária foi realizada dividindo-se em três grupos etários: 1 a 3 anos $(n=110), 3$ a 6 anos $(n=241)$ e maior que 6 anos $(n=181)$, onde 98,18\%, 90,87\% e 86,74\% dos animais foram positivos, respectivamente. Houve diferença significativa $(P<0,05)$ do grupo etário de 1 a 3 anos com os demais grupos, caracterizando que os animais jovens são menos susceptíveis à doença clínica que os animais mais velhos. Segundo a aptidão zootécnica $91,44 \%$ dos bovinos com aptidão para corte $(n=444)$ e $88,64 \%$ dos bovinos com aptidão para leite $(n=88)$ foram positivos. Em relação ao sexo, 90,54\% das fêmeas $(n=497)$ e $97,14 \%$ dos machos $(n=35)$ foram positivos. Não houve diferença significativa entre as aptidões 
zootécnicas e entre os sexos $(P>0,05)$. A prevalência entre os municípios diferiu significativamente $(P<0,0001)$, demonstrando que a infecção por B. bovis em bovinos não é homogênea na mesorregião. A soroprevalência encontrada caracteriza esta mesorregião como uma área de estabilidade enzoótica para B. bovis. Nesta circunstância epidemiológia faz-se necessário a imunização, apenas, de animais importados de outras áreas para esta mesorregião.

TERMOS DE INDEXAÇÃO: Soroepidemiologia, Babesia bovis, babesiose bovina, ensaio imunoenzimático, mesorregião Norte Fluminense, Brasil.

\section{INTRODUÇÃO}

As babesioses bovina nos países de clima tropical e subtropical, são causadas pelos hemoprotozoários Babesia bigemina (Smith \& Kilborne, 1893) e B. bovis (Babés, 1888). Estas são desencadeadas, principalmente, pela massiva destruição eritrocítica, decorrente dos aspectos biológicos dos agentes em realizarem parte de seu ciclo no interior destas células. $B$. bovis, típico pequeno babesiídeo dos bovinos é transmitido por larvas do carrapato Boophilus microplus. Este babesiídeo determina um quadro de anemia branda, palidez de mucosas, febre, sialorréia, depressão, disturbios neurológicos e tremores; muitas vezes mimetizando sintomas de outras enfermidades como a raiva dos bovinos e intoxicações por plantas causadoras de doenças neurológicas. A característica viscerotrópica bloqueante de $B$. bovis é que determina a gravidade da enfermidade, fenômeno que ao exame clínico não é percebido.

As babesioses são responsáveis por severos danos a sanidade animal com grande impacto econômico na pecuária bovina mundial (Kuttler 1988). A dinâmica da infecção por Babesia spp. é dependente de fatores como população de carrapatos infestantes; capacidade de transmissão do carrapato; susceptibilidade dos bovinos, que pode variar com a raça, idade, estado fisiológico e imunitário.

O estudo epidemiológico das babesioses bovina em uma determinada área é importante, pois pode revelar a possibilidade da ocorrência ou não de surtos. Os testes sorológicos são ferramentas imprecindíveis na avaliação da prevalência, condição imunológica e no controle de Babesia spp. assim como de carrapato transmissor (Mahoney 1975, Mahoney \& Ross 1972, Araújo et al. 1998). Embora a imunofluorescência (IF) seja a técnica considerada como referência para detecção de anticorpos anti Babesia spp., o ensaio imunoenzimático de adsorção (ELISA) é a prova que confere melhores resultados por ser mais sensível e específica (Barry et al. 1982, Araújo et al. 1998).

A situação epidemiológica das babesioses bovina no estado do Rio de Janeiro não é conhecida. Este estado possui um rebanho bovino efetivo, aproximado, de um milhão e oitocentos mil cabeças e, destes, cerca de $28,6 \%$ encontram-se na mesorregião Norte Fluminense (CIDE 1997). O presente estudo teve por propósito investigar, através do teste ELISA indireto, a prevalência de anticorpos anti $B$. bovis em bovinos na mesorregião Norte Fluminense do estado do Rio de Janeiro.

\section{MATERIAL E MÉTODOS}

Região estudada

O estudo foi conduzido com amostras de soro de bovinos de nove municípios da mesorregião Norte Fluminense do estado do Rio de Janeiro, segundo divisão político-administrativa da Fundação CIDE. A população estimada de bovinos desta mesorregião é de 518.465 cabeças, em uma área total de 663.198 hectares com a produção de leite de 81.806 .000 litros anuais (CIDE 1997).

Amostragem dos soros e divisão por grupos

As amostras de soros foram colhidas aleatoriamente de bovinos jovens e adultos, maiores que um ano de idade, aparentemente sadios, puros Bos indicus ou mestiço B. indicus $\times$ B. taurus. 0 tamanho da amostra foi determinado, por conveniência e facilidade de acesso à propriedade, tomando como parâmetro a coleta de no mímino um número maior ou igual a $0,1 \%$ da população total de bovinos da mesorregião. Coletou-se, assepticamente, o sangue de 532 animais por venopunção jugular e, os soros obtidos foram aliquotados em tubos tipo Eppendorfe armazenados à $-20^{\circ} \mathrm{C}$ até o momento da análise sorológica.

As 532 amostras de soro coletadas estão distribuídas entre nove municípios com a seguinte amostragem: Campos $(n=186)$, Macaé $(n=91)$, São Fidélis $(n=55)$, Carapebus $(n=10)$, Quissamã $(n=50)$, Conceição de Macabú $(n=27)$, São Francisco de Itabapoana $(n=69)$, Cardoso Moreira $(n=25)$ e São João da Barra $(n=19)$. Os animais estudados foram divididos por grupos; quanto à faixa etária: 1 a 3 anos $(n=110), 3$ a 6 anos $(n=241)$ e $>6$ anos $(n=181)$; quanto ao sexo: fêmeas $(n=497)$ e machos $(n=35)$ e quanto à aptidão zootécnica: animais com aptidão zootécnica para corte $(n=444)$ e animais com aptidão zootécnica para leite $(n=88)$.

Ensaio imunoenzimático (ELISA) indireto

Realizou-se o ensaio ELISA indireto para detecção de anticorpos da classe IgG anti Babesia bovis, utilizando-se microplacas de 96 orifícios para titulação. As microplacas foram sensibilizadas com extrato total antigênico de B. bovis, isolado do Mato Grosso do Sul em bezerros com parasitemia de 23,00\% (Kessler et al. 1987), segundo técnica descrita por Araújo et al. (1998), diluído em tampão carbonato pH 9,6. Os soros controles negativo e positivo, bem como os soros testes foram diluídos à 1:500 em tampão salino fosfatado com Tween 20 a $0,05 \%$ (PBST) $\mathrm{pH} \mathrm{7,4.} \mathrm{Adicionou-se} \mathrm{às} \mathrm{placas} \mathrm{conjugado} \mathrm{IgG} \mathrm{de}$ coelho anti IgG bovina marcada com fosfatase alcalina (Sigma Chemical) diluído em PBST pH 7,4. Utilizou-se como substratocromógeno para-nitrofenil fosfato (Sigma Chemical) diluído em tampão glicina $\mathrm{pH}$ 10,5. A leitura do ensaio foi realizada em espectrofotômetro multicanal para microplacas de 96 orifícios (Bio Rad Laboratories, model 550 Microplate Reader) ao comprimento de onda de $405 \eta \mathrm{m}$.

\section{Análise estatística}

Procedeu-se a análise estatística dos dados utilizando os testes de Fisher e Qui-quadrado $\left(\chi^{2}\right)$ com graus de confiança variando de acordo com o tipo de comparação. Para o ELISA a linha de corte (cutoff) foi estabelecida com o grau de confiança de $99,99 \%$, segundo a média mais três vezes o desvio padrão dos valores da densidade óptica dos controles negativos.

\section{RESULTADOS}

A análise soroepidemiológica das 532 amostras de soros revelou $484(90,98 \%)$ animais reagentes positivos ao ELISA indireto, com anticorpos da classe IgG anti Babesia bovis, dos quais: 
Quadro 1. Prevalência sorológica de anticorpos anti Babesia bovis em bovinos $(n=532)$ da mesorregião Norte Fluminense, determinada pelo ELISA indireto

\begin{tabular}{ccccc}
\hline \multirow{2}{*}{ Título } & \multirow{2}{*}{ Positivos (n) } & \multicolumn{2}{c}{ Prevalência } & \multirow{2}{*}{ Negativos (N) } \\
\cline { 3 - 4 } & & Relativa & Absoluta & \\
\hline $1: 500$ & 108 & $22,31 \%$ & $20,30 \%$ & - \\
$1: 1000$ & 190 & $39,26 \%$ & $35,72 \%$ & - \\
$1: 2000$ & 111 & $22,93 \%$ & $20,87 \%$ & - \\
$1: 4000$ & 39 & $8,06 \%$ & $7,33 \%$ & - \\
$1: 8000$ & 15 & $3,10 \%$ & $2,82 \%$ & - \\
$1: 16000$ & 14 & $2,89 \%$ & $2,63 \%$ & - \\
$1: 32000$ & 3 & $0,62 \%$ & $0,56 \%$ & - \\
$1: 64000$ & 4 & $0,83 \%$ & $0,75 \%$ & - \\
Total positivos & 484 & $100 \%(484 / 484)$ & $90,98 \%(484 / 532)$ & - \\
Total negativos & - & - & $9,02 \%(48 / 532)$ & 48
\end{tabular}

soropositivos, respectivamente, para os grupos de 1 a 3 anos, 3 a 6 anos e $>6$ anos de idade. Houve diferença significativa $(P<0,05)$ entre o grupo etário de 1 a 3 anos com os demais grupos, segundo o teste $\chi^{2}$ e o teste de Fisher (Quadro 2).

A análise estatística, segundo a aptidão zootécnica revelou a soroprevalência de $91,44 \%$ de positivos para os bovinos com aptidão para corte e $88,64 \%$ de soropositivos para os bovinos com aptidão para leite. Não houve diferença significativa entre as aptidões zootécnicas $(P>0,05)$ pelo teste $\chi^{2}$ e pelo teste de Fisher (Quadro 3).

Em relação a soroprevalência segundo o sexo, não houve diferença significativa $(P>0,05)$ pelo teste $\chi^{2}$ e pelo teste de Fisher, onde $90,54 \%$ das fêmeas e $97,14 \%$ dos machos foram reagentes positivos (Quadro 4).

Quadro 2. Prevalência sorológica de anticorpos anti Babesia bovis em bovinos $(\mathrm{n}=532)$, segundo a faixa etária, da mesorregião Norte Fluminense

\begin{tabular}{|c|c|c|c|c|c|c|}
\hline \multicolumn{7}{|c|}{ Faixa etária (anos) } \\
\hline & \multicolumn{2}{|c|}{$1-3(n=110)^{*} a$} & \multicolumn{2}{|c|}{$3-6(n=241) b$} & \multicolumn{2}{|c|}{$>6(\mathrm{n}=181) \mathrm{b}$} \\
\hline & Relativa & Absoluta & Relativa & Absoluta & Relativa & Absoluta \\
\hline Positivo & $\begin{array}{c}98,18 \% \\
(108 / 110)\end{array}$ & $\begin{array}{c}20,30 \% \\
(108 / 532)\end{array}$ & $\begin{array}{c}90,87 \% \\
(219 / 241)\end{array}$ & $\begin{array}{c}41,16 \% \\
(219 / 532)\end{array}$ & $\begin{array}{c}86,74 \% \\
(157 / 181)\end{array}$ & $\begin{array}{c}29,51 \% \\
(157 / 532)\end{array}$ \\
\hline Negativo & $\begin{array}{l}1,82 \% \\
(2 / 110)\end{array}$ & $\begin{array}{c}0,38 \% \\
(2 / 532)\end{array}$ & $\begin{array}{c}9,13 \% \\
(22 / 241)\end{array}$ & $\begin{array}{c}4,14 \% \\
(22 / 532)\end{array}$ & $\begin{array}{c}13,26 \% \\
(24 / 181)\end{array}$ & $\begin{array}{c}4,51 \% \\
(24 / 532)\end{array}$ \\
\hline Total & $\begin{array}{c}100 \% \\
(110 / 110)\end{array}$ & $\begin{array}{c}20,68 \% \\
(110 / 532)\end{array}$ & $\begin{array}{c}100 \% \\
(241 / 241)\end{array}$ & $\begin{array}{c}45,30 \% \\
(241 / 532)\end{array}$ & $\begin{array}{c}100 \% \\
(181 / 181)\end{array}$ & $\begin{array}{c}34,02 \% \\
(181 / 532)\end{array}$ \\
\hline
\end{tabular}

*Houve diferença significativa $(\mathrm{P}<0,05)$ entre as faixas etárias, segundo o teste $\chi^{2}$ e 0 teste de Fisher, representado por letras diferentes.

Quadro 3. Prevalência sorológica de anticorpos anti Babesia bovis em bovinos $(\mathrm{n}=532)$, segundo a aptidão zootécnica, da mesorregião Norte Fluminense

\begin{tabular}{|c|c|c|c|c|}
\hline & \multicolumn{4}{|c|}{ Aptidão zootécnica } \\
\hline & \multicolumn{2}{|c|}{ Corte $(n=444)^{a}$} & \multicolumn{2}{|c|}{ Leite $(\mathrm{n}=88)^{\mathrm{a}}$} \\
\hline & Relativa & Absoluta & Relativa & Absoluta \\
\hline Positivo & $\begin{array}{c}91,44 \% \\
(406 / 444)\end{array}$ & $\begin{array}{c}76,32 \% \\
(406 / 532)\end{array}$ & $\begin{array}{l}88,64 \% \\
(78 / 88)\end{array}$ & $\begin{array}{c}14,66 \% \\
(78 / 532)\end{array}$ \\
\hline Negativo & $\begin{array}{c}8,56 \% \\
(38 / 444)\end{array}$ & $\begin{array}{c}7,14 \% \\
(38 / 532)\end{array}$ & $\begin{array}{c}11,36 \% \\
(10 / 88)\end{array}$ & $\begin{array}{c}1,88 \% \\
(10 / 532)\end{array}$ \\
\hline Total & $\begin{array}{c}100 \% \\
(444 / 444)\end{array}$ & $\begin{array}{c}83,46 \% \\
(444 / 532)\end{array}$ & $\begin{array}{c}100 \% \\
(88 / 88)\end{array}$ & $\begin{array}{c}16,54 \% \\
(88 / 532)\end{array}$ \\
\hline
\end{tabular}

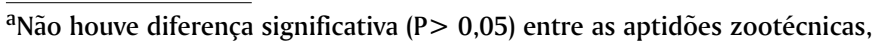
segundo o teste $\chi^{2}$ e o teste de Fisher.

20,30\% com título de 1:500,35,72\% com título de 1:1000, $20,87 \%$ com título de $1: 2000,7,33 \%$ com título de 1:4000, $2,82 \%$ com título de $1: 8000,2,63 \%$ com título de $1: 16000$, 0,56\% com título de 1:32000, 0,75\% com título de 1:64000 e 9,02\% foram negativos (Quadro 1).

A análise segundo a faixa etária, dividida em três grupos, revelou a prevalência relativa de $98,18 \%, 90,87 \%$ e $86,74 \%$
Quadro 4. Prevalência sorológica de anticorpos anti Babesia bovis em bovinos $(n=532)$, segundo o sexo, da mesorregião Norte Fluminense

\begin{tabular}{cccccc}
\hline & \multicolumn{3}{c}{ Sexo } & \\
\cline { 2 - 3 } & \multicolumn{2}{c}{ Fêmea $(\mathrm{n}=497)^{\mathrm{a}}$} & & \multicolumn{2}{c}{ Macho $(\mathrm{n}=35)^{\mathrm{a}}$} \\
\cline { 2 - 3 } \cline { 5 - 6 } Positivo & Relativa & Absoluta & & Relativa & Absoluta \\
\cline { 6 - 6 } & $90,54 \%$ & $84,59 \%$ & & $97,14 \%$ & $6,39 \%$ \\
\multirow{2}{*}{ Negativo } & $9,46 \%$ & $8,83 \%$ & & $2,86 \%$ & $0,19 \%$ \\
& $(449 / 497)$ & $(450 / 532)$ & & $(34 / 35)$ & $(34 / 532)$ \\
& & & & & \\
\multirow{2}{*}{ Total } & $100 \%$ & $93,42 \%$ & & $100 \%$ & $6,58 \%$ \\
& $(497 / 497)$ & $(497 / 532)$ & & $(35 / 35)$ & $(35 / 532)$
\end{tabular}

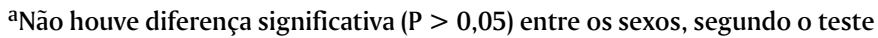
$\chi^{2}$ e o teste de Fisher.

A prevalência comparada entre os nove municípios diferiu significativamente $(P<0,0001)$ segundo o teste $\chi^{2}$, onde os animais dos municípios: Campos 91,94\% (171), Macaé 98,90\% (90), São Fidélis 98,18\% (54), Carapebus 90,00\% (9), Quissamã 100\%(50), Conceição de Macabú 100\% (27), São Francisco de Itabapoana 69,57\% (48), Cardoso Moreira 92,00\% (23) e São João da Barra 63,16\% (12) foram soropositivos (Fig. 1). 


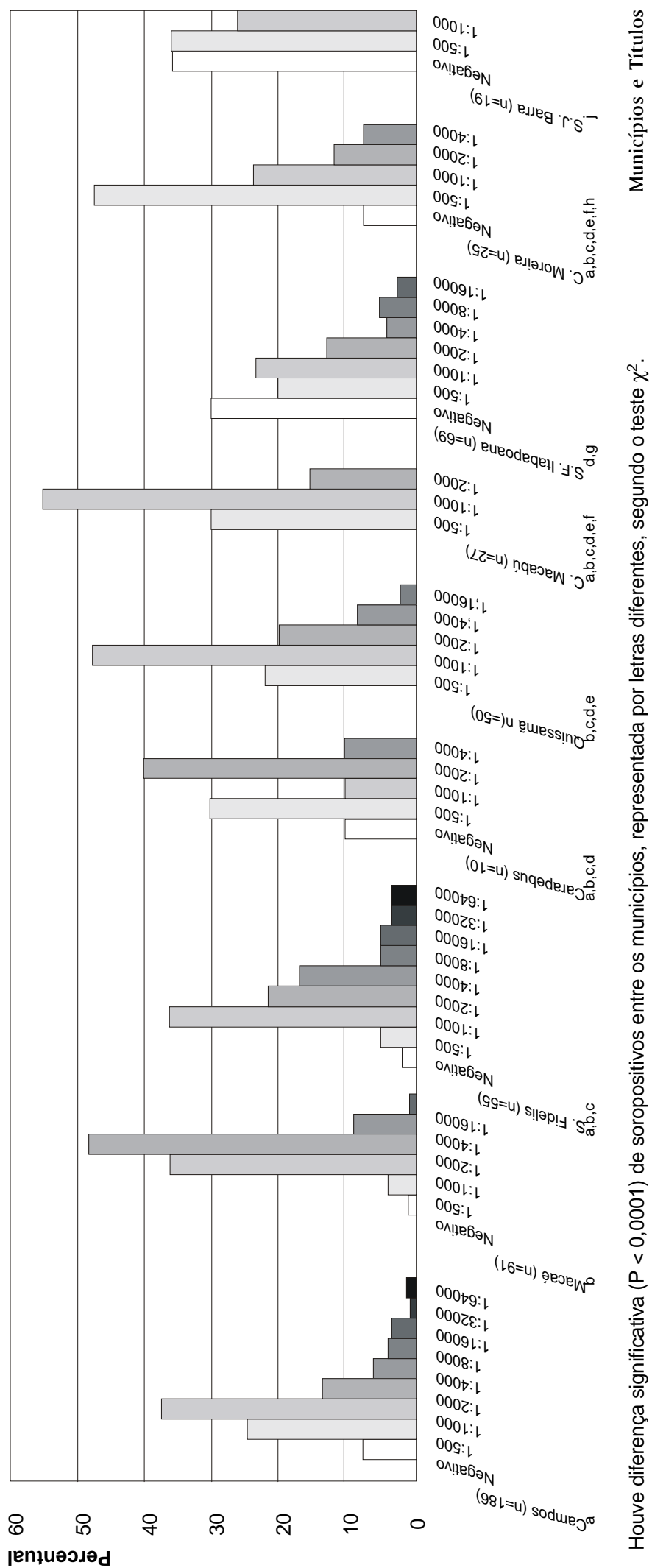

Fig 1. Prevalência de anticorpos anti Babesia bovis em bovinos $(\mathrm{n}=$ 532) da mesorregião Norte Fluminense. Distribuição segundo os municípios estudados.

\section{DISCUSSÃO}

A região estudada foi considerada como uma área de estabilidade enzoótica. Pois, a soroprevalência encontrada está acima do limite $(75,0 \%)$ para se considerar uma área como estável enzooticamente (Mahoney 1975). Este resultado é esperado, pois na maioria das áreas compreendidas entre os paralelos $32^{\circ}$ latitude sul e $40^{\circ}$ latitude norte os vetores de Babesia bovis, carrapatos do gênero Boophilus, estão amplamente difundidos (Mahoney \& Ross 1972, Kuttler 1988, Leite et al. 1989). A diferença significativa observada entre os animais jovens, quando comparada aos animais adultos pode ser justificada pois, a taxa de inoculação de $B$. bovis pelo $B$. microplus é naturalmente baixa (Mahoney 1967).

Embora na mesorregião estudada o perfil da pecuária bovina é predominantemente de corte, constituída na sua maioria por raças de origem indiana (Bos indicus) e seus mestiços (CIDE 1997), naturalmente resistentes a B. microplus (Mahoney 1975, Madruga et al. 1984a,b) e; embora existam fatores de resistência natural à babesiose (Levy et al. 1982), o percentual de animais com anticorpos anti $B$. bovis nesta região diminue com a idade. E, o fato dos bovinos com idade entre 1 a 3 anos serem mais soroprotegidos, pode estar relacionado à anticorpos colostrais ou associação destes com anticorpos de primo-infecção. Assim, faz-se necessário o controle da enfermidade com o acompanhamento sorológico, em animais adultos, para a identificação daqueles com baixos títulos de anticorpos, expostos à condição de risco (Mahoney \& Ross 1972, Mahoney 1975).

Na mesorregião Norte Fluminense do estado do Rio de Janeiro as análises quanto a aptidão zootécnica e quanto ao sexo demonstraram não haver diferença estatística significativa na prevalência de anticorpos. Sendo, portanto, a infecção por $B$. bovis alta, enzoótica e em equilíbrio, entre os grupos analisados. Estas observações sugerem que estes parâmetros não interferem epidemiologicamente na prevalência do hemoprotozoário nesta mesorregião.

Prevalências maiores ou iguais a 75\% de soropositivos significam que os animais se infectam antes de um ano de idade com posteriores infecções e, um número mínimo de animais adultos pode apresentar babesiose clínica (Mahoney \& Ross 1972, Madruga et al. 1984b). Assim, a diferença estatística observada na mesorregião Norte Fluminense, quanto a prevalência de positivos anti $B$. bovis, implica inferir que em alguns municípios desta área (Fig. 1) os animais estão mais expostos à condição de risco na ocorrência de surtos de babesiose, pois a infecção por $B$. bovis em bovinos não é homogênea entre os municípios. Entretanto, este risco é mínimo; exceto, quando há introdução de animais provenientes de áreas livres ou de áreas instáveis enzooticamente. Nesta situação, é necessário a imunização de animais importados oriundos dessas áreas. 0 conhecimento dos níveis de anticorpos, anti $B$. bovis, em bezerros nesta mesorregião elucidaria a origem dos anticorpos e auxiliaria na compreensão do perfil imunológico do rebanho.

Estima-se que aproximadamente 130 milhões de bovinos estão sujeitos à infecção por $B$. bovis e por $B$. bigemina e que a 
maior parte do território brasileiro está sob condição de estabilidade enzoótica (MARA 1985, Patarroyo et al. 1987, Leite et al. 1989, Linhares et al. 1992). A distribuição de Babesia spp., parasita de bovinos, está associada à presença do carrapato $B$. microplus e a prevalência é elevada em algumas regiões do país (Valente \& Amaral 1971, Madruga et al. 1984a,b, Alves 1987). No entanto, mesmo em regiões com estabilidade enzoótica a infecção por $B$. bovis é considerada como causa de doença e mortalidade em bezerros (Valente \& Amaral 1971, Ribeiro et al. 1983, Madruga et al. 1984a).

Os resultados obtidos não diferem de outros estados do país, onde a infecção por $B$. bovis é alta independente de fatores etário, sexual e racial; embora, no presente trabalho tenha havido diferença entre as idades analisadas. Poucas regiões do Brasil possui situação de instabilidade para $B$. bovis, como em Pernambuco onde a prevalência é de $27,80 \%$ (Alves 1987). No estado de Goiás foi observado a prevalência de anticorpos de $98,72 \%$ (Linhares et al. 1992), na Bahia foi de 95,30\% (Araújo et al. 1998) e no estado de Minas Gerais a prevalência de anticorpos anti $B$. bovis foi de $82,50 \%$ (Patarroyo et al. 1987), análises determinadas pela prova de IF indireta.

Em um estudo comparativo entre as técnicas ELISA indireto, IF indireto e o teste de conglutinação rápida, para deteç̧ão de anticorpos anti B. bovis, conduzido com 462 bovinos de quatro microrregiões do estado da Bahia, observouse ser ELISA o teste mais eficiente (Araújo et al. 1998). Böse et al. (1990) verificaram que ELISA e a prova mais indicada no diagnóstico sorológico, de rebanhos, para $B$. bovis, mesmo utilizando antígenos brutos. Esta técnica é ainda recomendada para uso em áreas estáveis como também em áreas instáveis enzooticamente (Madruga et al. 1997).

$O$ teste ELISA indireto utilizado mostrou-se adequado na deteç̧ão e diferenciação dos níveis de anticorpos anti $B$. bovis em bovinos da mesorregião estudada, podendo o mesmo ser indicado para outras regiões e situações epidemiológicas.

\section{REFERÊNCIAS}

Alves L.C. 1987. Prevalência de babesiose em gado leiteiro no município de Garanhuns, estado de Pernambuco. Tese de Mestrado, Fac. Med. Vet. Zootec., USP, São Paulo. 124p.

Araújo F.R., Madruga C.R., Leal C.R.B., Schenk M.A.M., Kessler R.H., Marques A.P.C. \& Lemaire D.C. 1998. Comparison between enzyme-linked immunosorbent assay, indirect fluorescent antibody and rapid conglutination tests in detecting antibodies against Babesia bovis. Vet. Parasitol. 74: 101-108.

Barry D.N., Rodwell B.J., Timms P. \& McGregor W. 1982. A microplate enzyme immunoassay for detecting and measuring antibodies to Babesia bovis in cattle serum. Aust. Vet. J. 59: 136-140.

Böse R., Jacobson R.H., Gale K.R., Waltisbuhl D.J. \& Wright I.G. 1990. An improved ELISA for the detection of antibodies against Babesia bovis using either a native or a recombinant B. bovis antigen. Parasitol. Res. 76: 648652.

CIDE 1997. Território, Rio de Janeiro. Fundação de Informação e Dados do Rio de Janeiro. 80p.

Kessler R.H., Madruga C.R., Jesus E.F. \& Semprebom D.V. 1987. Isolamento de cepas puras de Babesia bovis, Babesia bigemina e Anaplasma marginale em área enzoótica. Pesq. Agropec. Bras. 22: 747-752.

Kuttler L.K. 1988. World-wide impact of babesiosis, p. 1-22. In: Ristic M. (ed.) Babesiosis of Domestic Animals and Man. CRC Press, New York.

Leite A.M.O., Arnoni J., Silva S.S., Farias N., Cruz H. \& Nishikawa H. 1989. Serological study of bovine babesiosis in a marginal area of Brasil. Proc. 8th National Veterinary Hemoparasite Disease Conference, St. Louis, p. 624-635.

Levy M.G., Clabaugh G. \& Ristic M. 1982. Age resistence in bovine babesiosis: role of blood factors in resistence to Babesia bovis. Infect. Immun. 37(3): 1127-1131.

Linhares G.F.C., Massard C.L., Araújo J.L.B. \& Alves L.C. 1992. Levantamento sorológico para Babesia bigemina (Smith \& Kilborne, 1893) e Babesia bovis (Babés, 1888) em bovinos da região Centro-Oeste do Brasil. Arq. Univ. Fed. Rural do Rio de Janeiro 15: 85-91.

Madruga C.R., Gomes R.F. \& Schenk M.A.M. 1984a. Etiologia de algumas doenças de bezerros de corte no estado de Mato Grosso do Sul. Circular Técnica 15, Embrapa-CNPGC, Campo Grande, MS. 27p.

Madruga C.R., Aycardi E., Kessler R.H., Schenk M.A.M. \& Figueredo G.R. 1984b. Níveis de anticorpos anti Babesia bigemina e Babesia bovis em bezerros da raça nelore, ibagé e cruzamentos de nelore. Pesq. Agropec. Bras. 19(9): 1163-1168.

Madruga C.R., Marques A.P.C., Queiroz R.A. \& Vaz E.C. 1997. Avaliação de um teste ELISA para detecção de anticorpos contra Babesia bigemina em bovinos de áreas de estabilidade e instabilidade enzoótica. Revta Bras. Parasitol. Vet. 6 (Supl.1): 302.

Mahoney D.F. 1967. Bovine babesiosis: preparation and assessment of complement fixing antigens. Exp. Parasitol. 20: 232-241.

Mahoney D.F. \& Ross D.R. 1972. Epizootiological factors in the control of bovine babesiosis. Aust. Vet. J. 48: 292-298.

Mahoney D.F. 1975. The diagnosis of babesiosis in Australia, p. 49-62. In: Wells E.A. (ed.) Workshop on Hemoparasites (Anaplasmosis and Babesiosis). CIAT, Cali, Colombia.

MARA 1985. Secretaria de Defesa Sanitária Animal, Carrapato, berne e bicheira no Brasil. Ministério da Agricultura e Reforma Agrária (MARA), Brasília. 153p.

Patarroyo J.H., Ribeiro M.FB. \& Santos J.L. 1987. Epidemiologia das babesioses bovinas no estado de Minas Gerais. I. Prevalência de anticorpos fluorescentes na "Zona da Mata", MG. Arq. Bras. Med. Vet. Zootec. 39: 423-429.

Ribeiro M.F.B., Salcedo J.H.P., Santos J.L \& Faria J.E. 1983. Inquérito de opinião com criadores da Zona da Mata do estado de Minas Gerais: I. Alguns fatores associados com mortalidade de bezerros. Arq. Bras. Med. Vet. Zootec. 35: 547-5569.

Valente F.A.T. \& Amaral L.B. 1971. Ocorrência de moléstia nos rebanhos bovinos do estado de São Paulo no triênio 1965/67. V. Piroplasmose e anaplasmose na região de São Paulo, Sorocaba e Bauru, SP. Biológico, São Paulo, 37: 84-90. 